\title{
Vitamin D in Hashimoto's thyroiditis and its relationship with thyroid function and inflammatory status
}

\author{
Ilka Mara Borges Botelho ${ }^{1)}$, Arnaldo Moura Neto'), Conceição Aparecida Silva' ${ }^{2)}$, \\ Marcos Antônio Tambascia ${ }^{1)}$, Sarah Monte Alegre ${ }^{3)}$ and Denise Engelbrecht Zantut-Wittmann ${ }^{1)}$ \\ 1) Endocrinology Division, Department of Internal Medicine, Faculty of Medical Sciences, University of Campinas, Campinas, San \\ Paulo, Brazil \\ 2) Biology Institute, University of Campinas, Campinas, San Paulo, Brazil \\ 3) Metabolic Unit, Department of Internal Medicine, Faculty of Medical Sciences, University of Campinas Campinas, San Paulo, \\ Brazil
}

\begin{abstract}
Several studies have shown the correlation between vitamin D [25(OH)D] deficiency and thyroid autoimmunity and reducing of thyroid autoantibodies in patients with normal levels of vitamin D combining with thyroid hormone replacement. However, other authors not agree with this association. It is still unclear whether the low 25(OH)D levels are the result of HT disease or a part of its cause. We studied 88 patients with HT regarding vitamin D status and thyroid autoimmunity markers as well as the relationship with cytokines produced by Th1, Th2, and Th17 cells compared with a control group of 71 euthyroid healthy subjects. The present study demonstrated that vitamin D concentrations were similar in patients HT and the control group. The reduction of free T4 levels was a predictor of vitamin D insufficiency for Hashimoto's thyroiditis, but not for the control group. Lower concentrations of TNF- $\alpha$ was a predictor of lower levels of vitamin D. Differences in the association between HT and vitamin D insufficiency remain unresolved in the literature. The thyroid hormone status would play a role in the maintenance of vitamin D sufficiency, and its immunomodulatory role would influence the presence of autoimmune thyroid disease. The positive correlation between free T4 and vitamin D concentrations suggests that adequate levothyroxine replacement in HT would be an essential factor in maintaining vitamin D at sufficient levels.
\end{abstract}

Key words: Hashimoto's thyroiditis, Cytokines, Vitamin D, Autoimmunity

HASHIMOTO'S THYROIDITIS (HT) is one of the autoimmune thyroid diseases (AITDs), also called chronic lymphocytic thyroiditis. Autoimmune attack on the thyroid plays with infiltration of the gland by $\mathrm{T}$ and B lymphocytes associated with thyroid peroxidase antibodies (TPO-Ab) and thyroglobulin antibodies (TG-Ab) production [1-5].

In HT occurs a genetic defect in $\mathrm{T}$ cell suppressor (Treg) function and CD4+ T cells are not deleted when they are free to promote activation of B-lymphocytes. Concomitantly, the Th cells produce cytokines that

Submitted Apr. 28, 2018; Accepted Jun. 26, 2018 as EJ18-0166 Released online in J-STAGE as advance publication Jul. 27, 2018 Correspondence to: Ilka Mara Borges Botelho, Endocrinology Division, Department of Internal Medicine, Faculty of Medical Sciences, University of Campinas, 126 Tessália Vieira de Camargo St, Campinas, San Paulo 13083-887, Brazil.

E-mail: ilkamara@hotmail.com induce thyrocytes to express surface antigens HLA-DR making them susceptible to immune attack. There is an interaction between susceptibility genes and environmental factors associated with autoimmune dysfunction [1-3, 6].

Th1 cells secrete inflammatory cytokines such as interferon- $\gamma$ (IFN- $\gamma$ ), interleukin-2 (IL-2), and tumor necrosis factor alpha (TNF- $\alpha$ ), essential for the cellmediated immune response. Th2 cells secrete the inflammatory cytokines IL-4 and IL-5, necessary for the antibody-mediated immune response. Th-17, another Th cell subtype composed of CD4+ T lymphocytes shows involvement in the pathophysiology of autoimmune diseases, especially in HT, and the production of interleukins such as IL-17 and IL-23 [2, 7-9].

HT manifests clinically in goiter or non-goiter (or atrophic) forms. The goiter form is related to the predominance of cellular immunity through activation of 
Th1 promoting apoptosis of the thyroid follicular cells leading to the dysfunction. The non-goiter form is related to the predominance of humoral immunity, via activation of Th2 that induces antigen-specific B lymphocytes to produce anti-TSH receptor antibodies (TRAb) stimulus blockers thus causing the disease $[3,10]$.

Several studies have shown the correlation between vitamin D deficiency and thyroid autoimmunity. Vitamin D3 (cholecalciferol) is produced in the skin when in the presence of ultraviolet-B radiation (UVB) and can also be obtained through supplementation and diet. There is a hydroxylation in the liver and an action of 1 alphahydroxylase in the kidney for product its active form calcitriol $\left(1,25(\mathrm{OH})_{2} \mathrm{VitD}\right)$, that binds to the nuclear vitamin D receptor (VDR), which is expressed in various immune cells such as monocytes, macrophages, dendritic cells, B and T lymphocytes, promoting immunomodulatory actions. Low concentrations of vitamin D are associated with predisposition to various autoimmune diseases such as type 1 diabetes mellitus, rheumatoid arthritis, multiple sclerosis and autoimmune thyroid diseases (AITDs). There are reports on the association between low vitamin D levels and the presence of TPO-Ab as well as the association of polymorphisms in the VDR gene in patients with AITDs. Calcitriol inhibits proliferation of Th1 cells and production of cytokines as well as induces B cell apoptosis [3, 11-21].

Multiple factors influence the synthesis of vitamin D through the skin such as duration of sun exposure, latitude, season, time of day, pigmentation of the skin, use of sunscreen, behavioral habits and diet. The reference values for vitamin $\mathrm{D}$ concentrations in our setting were recently reviewed, being considered as vitamin D insufficiency values below $20 \mathrm{ng} / \mathrm{mL}$ [22-25].

Many studies have shown reducing of thyroid autoantibodies in patients with normal levels of vitamin D combining with thyroid hormone replacement. However, other authors not agree with this association. It is still unclear whether the low 25(OH)D levels are the result of HT disease or a part of its cause [26-28].

Considering the possible role of vitamin D in thyroid autoimmunity, we aimed to study the relationship of vitamin D with thyroid function and inflammatory status in patients with HT.

\section{Methods}

\section{Study design}

We studied patients with HT regarding vitamin D sta- tus and thyroid autoimmunity markers as well as the relationship with cytokines produced by Th1, Th2 and Th17 cells compared with a control group of euthyroid healthy subjects.

An interim analysis was conducted to evaluate the statistical power of correlation between thyroid hormone, vitamin $\mathrm{D}$ and thyroid autoimmunity markers resulting in the minimum of 88 patients. Then, we included 88 patients with HT followed in our university hospital and 71 individuals without AITD, all aged 18 to 65 years. Blood samples were collected from the two groups for measurements of serum total $25 \mathrm{OH}$ vitamin $\mathrm{D}$, thyrotropin (TSH), free thyroxine (FT4), calcium, phosphorus, parathormone (PTH), TPOAb, TGAb, and TRAb. Cytokines produced by Th1 cells (IL-2, IFN- $\gamma, \mathrm{TNF}-\alpha$ ), Th2 (IL-4, IL-5) and Th17 (IL-17) were measured in all participants.

Ultrasound estimated thyroid volume in patients. Data on weight, height, body mass index, parity and time since direct interview collected diagnosis. Written informed consent was obtained from each patient or subject after full explanation of the purpose and nature of all procedures. The University Ethics in Research Committee approved the study.

\section{Inclusion criteria}

Only patients with the diagnosis of HT were included in the study.

The diagnosis of thyroid dysfunction was based on high concentrations of TSH and low FT4. At the time of collection, all patients with HT were on replacement therapy with levothyroxine. Only patients with high levels of antithyroid antibodies confirming the etiology of AITD were included.

All subjects in the control group were clinical and laboratory euthyroid, TPOAb, TGAb and TRAb undetectable and were selected from patient's companions or hospital staff.

\section{Exclusion criteria}

Exclusion criteria were: previous history of thyroidectomy, acutely ill patients, active malignant or inflammatory disease, use of amiodarone, steroids, calcium and/or vitamin $\mathrm{D}$, use of iodinated contrast less than 3 months before the start of the study, heart failure (class III or IV NYHA), severe liver disease (reduced albumin or increased INR), advanced kidney disease (stage 4 or 5), patients under hemodialysis, seropositive for HIV or hepatitis $\mathrm{C}$, and pregnant. 


\section{Laboratory evaluation of thyroid and vitamin $D$ status}

For evaluation of thyroid status, TSH was measured by electrochemiluminescence (Roche Cobas Elecsysreference values RV 0.41 to $4.5 \mu \mathrm{UI} / \mathrm{mL}$ ) and FT4 dosed by competitive chemiluminescence immunoassay Elecsys FT4 II (RV 0.9 and $1.8 \mathrm{ng} / \mathrm{mL}$ ). The intra-assay coefficient of variation $(\mathrm{CV})$ was $5 \%$; measuring range $0.01-$ $100 \mu \mathrm{UI} / \mathrm{mL}$, analytical sensitivity $0.01 \mathrm{pg} / \mathrm{mL}$ and functional sensitivity $0.014 \mu \mathrm{UI} / \mathrm{mL}$ with inter-assay $\mathrm{CV}$ of $20 \%$. For FT4 measurement interval was used between 0.02 to $7.76 \mathrm{ng} / \mathrm{dL}$, intra-assay CVs of $5 \%$ analytical sensitivity $0.023 \mathrm{ng} / \mathrm{mL}$ and functional $0.39 \mathrm{ng} / \mathrm{mL}$ and inter-assay CV 20\%. TPOAb and TGAb were measured by chemiluminescent immunometric assay Elecsys (RV up to $34 \mathrm{UI} / \mathrm{mL}$ and up to $115 \mathrm{IU} / \mathrm{mL}$, respectively). For TPOAb, measurement interval was 5.0 to $600.0 \mathrm{IU} / \mathrm{mL}$, CV 5\% analytical sensitivity 5.0 IU/mL Functional 34 $\mathrm{IU} / \mathrm{mL}$. For TGAb measurement interval was between 10.0 to $4,000.0 \mathrm{IU} / \mathrm{mL}$ ( $5 \% \mathrm{CV})$; analytical sensitivity 10 $\mathrm{IU} / \mathrm{mL}$ and functional sensitivity $34 \mathrm{IU} / \mathrm{mL}$. TRAb was measured by competitive electrochemiluminescence immunoassay using Elecsys TRAb TSH receptors (RV up to $1.22 \mathrm{IU} / \mathrm{L})$; measurement interval range from 0.3 to $40.0 \mathrm{IU} / \mathrm{L}, \mathrm{CV} 5 \%$; analytical sensitivity of $0.3 \mathrm{IU} / \mathrm{L}$ and functional sensitivity of $0.9 \mathrm{IU} / \mathrm{L}$. Total vitamin D (25OHVitD) was measured by the test LIAISON ${ }^{\circledR} 25 \mathrm{OH}$ Vitamin D TOTAL using chemiluminescent immunoassay technology (CLIA) for the quantitative determination of 25-hydroxyvitamin D and other hydroxylated metabolites of vitamin D in human serum, plasma or EDTA plasma with lithium heparin using the evaluation of the amount of vitamin D using the family LIAISON ${ }^{\circledR}$ analyzers.

We adopted the following recommendations for TSH levels: patients $<60$ years old $1.0-2.5 \mathrm{mU} / \mathrm{L}$; between 60-70 years 3-4 mU/L and $>70$ years 4-6 mU/L [29].

Vitamin D levels between 30 and $60 \mathrm{ng} / \mathrm{mL}$ are recommended for at-risk groups as patients with autoimmune diseases and were adopted as adequate to the study population [22].

\section{Cytokines evaluation}

Cytokines were measured by the immunoassay technique of Milliplex Map based on the Luminex Xmap technology. Luminex uses proprietary techniques to internally color-code microspheres with two fluorescent dyes. Through precise concentrations of these dyes, distinctly colored bead sets polystyrene microspheres or magnetic microspheres can be created, each of which is coated with a specific capture antibody. The reference values of cytokines are described below: IL-2 RV 1.0-1.6 pg/mL; INF- $\gamma$ RV $0.8-1.1 \mathrm{pg} / \mathrm{mL}$; TNF- $\alpha$ RV $0.7-1.1 \mathrm{pg} / \mathrm{mL}$; IL-4 RV 4.5-7.1 pg/mL; IL-5 RV 0.5-0.7 pg/mL; IL-17 RV 0.7-1.2 pg/mL.

\section{Thyroid ultrasound evaluation}

The total thyroid volume was determined in milliliters $(\mathrm{mL})$ by the product of the longitudinal, transverse and anteroposterior measurements multiplied by the constant 0.52 , adding up the volumes of the right and left lobes and isthmus. Values between 6 and $15 \mathrm{~mL}(10-11 \pm 3-4$ $\mathrm{mL}$ ) were considered normal for adults [30].

\section{Statistical methods}

Exploratory data analysis was performed through summary measures (frequency, percentage, mean, standard deviation, minimum, median and maximum). The groups were compared using Kruskal-Wallis, Chi-Square or Fisher's exact test. The correlation of Vitamin D and Interleukins with the other variables was evaluated using the Spearman coefficient or the Mann-Whitney test. Factors associated with vitamin D deficiency were assessed through logistic regression using the stepwise selection criteria. The significance level for statistical analysis was $5 \%[31-33]$.

\section{Results}

\section{Descriptive analysis}

The study included 159 participants, 88 patients with HT, of which 82 were female $(93 \%)$. In the control group, there were 71 subjects, 61 female (85.9\%). Meantime of diagnosis of HT was ten years (range 1-47 years). Clinical and laboratory characteristics of patients and control groups are described in Table 1.

Vitamin D levels below $30 \mathrm{ng} / \mathrm{dL}$ were found in $59.1 \%$ $(n=39)$ of the control group and in $71.8 \%(n=61)$ of HT group $(p=0.1024)$.

\section{Comparative analysis}

There was no significant difference between levels of vitamin $\mathrm{D}$, calcium, phosphorus or parathormone when comparing the two groups. TSH concentrations were higher in patients compared to the control group as expected, with no difference in free T4. We did not find differences related to gender, alcohol consumption or cigarette smoking (Table 1 ). 
Table 1 Demographic and laboratory characteristics of HT and control group [mean (min-max)*]

\begin{tabular}{|c|c|c|c|}
\hline Characteristics & Patients HT $(n=88)$ & Control Group $(n=71)$ & $p$ \\
\hline Age (years)* & $46.2(20-66)$ & $47.4(19-77)$ & 0.5346 \\
\hline Gender $(\mathrm{F} / \mathrm{M})(n)$ & $82 / 06$ & $61 / 09$ & 0.1983 \\
\hline $\operatorname{BMI}\left(\mathrm{Kg} / \mathrm{m}^{2}\right)^{*}$ & $28.1(16.8-45.5)$ & $26.4(17-42.6)$ & 0.0516 \\
\hline Time of diagnosis (years)* & $10.6(1-47)$ & - & - \\
\hline Alcohol consumption* & $1(1.2 \%)$ & $0(0 \%)$ & 1.000 \\
\hline Smoking* & $9(11 \%)$ & $12(19 \%)$ & 0.2148 \\
\hline \multirow{2}{*}{ FT4 (ng/dL)* } & $1.2(0.5-1.8)$ & $1.2(0.8-1.6)$ & \multirow{2}{*}{0.4510} \\
\hline & Median: 1.2 & Median: 1.2 & \\
\hline \multirow{2}{*}{$\mathrm{TSH}(\mu \mathrm{UI} / \mathrm{mL})^{*}$} & $6.3(0.3-57)$ & $2.0(0.6-5.0)$ & \multirow{2}{*}{$<0.0001$} \\
\hline & Median: 3.3 & Median: 1.7 & \\
\hline $\mathrm{TPOAb}(\mathrm{UI} / \mathrm{mL})^{*}$ & $571.4(30-3,000)$ & 一 & - \\
\hline $\operatorname{TGAb}(\mathrm{UI} / \mathrm{mL})^{*}$ & $677.3(100-4,000)$ & - & - \\
\hline $\mathrm{TRAb}(\mathrm{UI} / \mathrm{L})^{*}$ & $1.9(0.2-40)$ & - & 一 \\
\hline Calcium $(\mathrm{mg} / \mathrm{dL}) *$ & $9.1(7.6-10.4)$ & $9.1(8.5-10.1)$ & 0.9194 \\
\hline Phosphor (mg/dL)* & $3.3(2.0-5.4)$ & $3.4(2.5-4.5)$ & 0.1486 \\
\hline PTH $(\mathrm{pg} / \mathrm{mL})^{*}$ & $41.4(8.4-207)$ & $38.4(11-127.1)$ & 0.3779 \\
\hline 25OHVitaminD $(\mathrm{ng} / \mathrm{mL})^{*}$ & $26.4(7.6-48.2)$ & $28.6(13-51.2)$ & 0.1917 \\
\hline Vitamin D Insufficiency & $61(71.8 \%)$ & $39(59.1 \%)$ & 0.1024 \\
\hline
\end{tabular}

Mann-Whitney; Chi-square; Fisher exact test

Table 2 Serum concentrations of interleukins Th1 (IL-2, TNF- $\alpha$, IFN- $\gamma$ ), Th2 (IL-4, IL-5) and Th17 (IL-17) in HT and control group [mean (min-max)]

\begin{tabular}{lccc}
\hline Interleukins & HT $(n=88)$ & Control Group $(n=71)$ & $p$ \\
\hline IL-2 $(\mathrm{pg} / \mathrm{mL})$ & $0.7(0.1-7.3)$ & $0.6(0.1-5.7)$ & 0.9556 \\
IL-4 $(\mathrm{pg} / \mathrm{mL})$ & $50.4(1-330.2)$ & $48.0(0.9-378.3)$ & 0.2067 \\
IL-5 $(\mathrm{pg} / \mathrm{mL})$ & $1.6(0.0-15.5)$ & $1.6(0.0-20.8)$ & 0.3597 \\
TNF- $\alpha(\mathrm{pg} / \mathrm{mL})$ & $13.3(0.2-35)$ & $11.8(0.2-35.5)$ & 0.0904 \\
IFN- $\gamma(\mathrm{pg} / \mathrm{mL})$ & $17.0(0.1-228)$ & $13.4(0.1-152)$ & 0.9165 \\
IL-17 $(\mathrm{pg} / \mathrm{mL})$ & $13.9(0.1-176)$ & $12.3(0.1-177)$ & 0.6157 \\
\hline
\end{tabular}

Mann-Whitney test

We did not observe differences between the concentrations of interleukins (Table 2).

\section{Correlations}

\section{Hashimoto's Thyroiditis}

A positive correlation was observed between vitamin D and free T4, IL-17, TNF- $\alpha$ and IL-5 (Table 3). There was no significant correlation between vitamin $\mathrm{D}$ and other immunological markers, phosphorus or TSH (data not shown). We also found no correlation between vita$\min \mathrm{D}$ and PTH $(r=-0.07044 ; p=0.5373)$.

TNF- $\alpha$ was positively correlated with thyroid volume. IFN- $\gamma$ correlated positively with TPOAb and negatively with calcium. IL-5 and IL-17 correlated negatively with TRAb (Table 3). There was no correlation between interleukins and age, BMI, diagnostic time, parity, TSH, free T4, TPOAb, TGAb, phosphorus or PTH (data not shown).

Among these patients, $58(66.7 \%)$ presented a nongoiter form $($ mean $=8.3 \mathrm{~mL})$ and $29(33.3 \%)$, the form with goiter $($ mean $=24.62 \mathrm{~mL})$. In the subgroup with goiter there was a negative correlation of volume with IL-2 (Th1) concentrations $(r=-0.47330 ; p=0.0146)$. The volume did not correlate with other interleukins or vitamin $\mathrm{D}$ in both subgroups.

\section{Control Group}

In the control group, there was a negative correlation between vitamin $\mathrm{D}$ and age $(r=-0.31374, p=0.013)$ whereas there was no correlation between vitamin $\mathrm{D}$ and interleukins, thyroid hormone profile or phosphorus 
Table 3 Correlations between interleukins, vitamin D and variables in HT. Correlation coefficients (Spearman's rho)

\begin{tabular}{|c|c|c|c|c|c|c|}
\hline & & Thyroid volume & Calcium & TRAb & TPOAb & Vitamin D \\
\hline \multirow{2}{*}{$\mathrm{IFN}-\gamma$} & $r$ & & -0.21906 & -0.22278 & 0.24208 & \\
\hline & $p$ & & 0.0415 & 0.0381 & 0.0265 & \\
\hline \multirow[t]{2}{*}{ TNF- $\alpha$} & $r$ & 0.22508 & & & & 0.37505 \\
\hline & $p$ & 0.0372 & & & & 0.0004 \\
\hline \multirow[t]{2}{*}{ IL-17 } & $r$ & & & -0.26848 & & 0.3505 \\
\hline & $p$ & & & 0.0119 & & 0.0011 \\
\hline \multirow[t]{2}{*}{ IL-5 } & $r$ & & & -0.30565 & & 0.2661 \\
\hline & $p$ & & & 0.004 & & 0.0144 \\
\hline \multirow[t]{2}{*}{ FT4 } & $r$ & & & & & 0.25199 \\
\hline & $p$ & & & & & 0.0224 \\
\hline
\end{tabular}

$r$ : correlation $p$ : estatistical significance level

(data not shown). Still, we did not find correlation between vitamin $\mathrm{D}$ and $\mathrm{PTH}$ in the controls $(r=$ $-0.16112 ; p=0.1998)$.

\section{Analysis of logistic regression}

In HT group, simple logistic regression analysis showed FT4 (OR $=0.063 ; p=0.0066$, CL 95\%: 0.009$0.464)$ and TNF- $\alpha(\mathrm{OR}=0.907, p=0.0130, \mathrm{CL} 95 \%$ : $0.840-0.980$ ) at lower levels as predictive factors of reduction of vitamin D levels. There were no significant values between vitamin $\mathrm{D}$ insufficiency and the other variables. In the multiple logistic regression analysis, lower levels of free T4 was a risk factor for vitamin D insufficiency $(\mathrm{OR}=0.076 ; 95 \% \mathrm{CI}: 0.008-0.764, p=$ 0.0286).

A receiver operator characteristic (ROC) curve was built to discriminate the best threshold for concentrations of free T4 to discriminate insufficiency and sufficiency of vitamin D. We found a threshold of $1.18 \mathrm{ng} / \mathrm{dL}$, with an accuracy of $70.8 \%$, specificity of $82.6 \%$ and sensitivity of $55.9 \%$ (Fig. 1).

In the control group, after simple logistic regression analysis, it was verified that, age $(\mathrm{OR}=1.051, p=$ 0.0182, CL 95\%: 1.008-1.095) and IL-4 (OR $=1.013$, $p=0.0415$, CL 95\%: 1.000-1.026) were predictive factors of vitamin D insufficiency. There were no significant values between lower levels of vitamin $\mathrm{D}$ and the other variables: sex, smoking, parity, calcium, phosphorus, PTH, TSH, free T4 and other interleukins studied. There were no risk factors in the multiple logistic regression analysis for the control group.

\section{Discussion}

The present study demonstrated that vitamin D concentrations were similar in patients HT and the control group. Similarly, D'Aurizio et al. revealed no differences in vitamin D deficiency and 25OHD levels between 100 AITDs patients (52 TH and $48 \mathrm{GD}$ ) and healthy controls. Goswami et al. reported no association of vitamin D deficiency and TPOAb positivity, but only a weak inverse correlation between serum 25OHD and TPOAb levels in 642 patients. Effraimids et al. developed a longitudinal study of 803 AITDs subjects who concluded that vitamin $\mathrm{D}$ deficiency was not associated with the early stages of thyroid autoimmunity. Yasmeh et al. reported a higher prevalence of sufficient vitamin D levels in HT females relative to control, observed a significant positive correlation between vitamin $\mathrm{D}$ and TPOAb levels in HT males relative to control concluding that HT was not associated with vitamin D deficiency relative to the control group. Zhang et al. pointed out that Vitamin D status was not associated with positive thyroid autoantibodies in a cross-sectional study. Higher vitamin D levels were associated with lower TSH levels in males. On the other hand, Ma et al. (2015) evaluated the association between vitamin D concentrations and AITDs (GD, HT, and postpartum thyroiditis) in two independent casecontrol studies, observing a decrease in vitamin D levels in these patients when compared to controls. Metaanalysis of Wang (2015) and the Mazokopakis review (2014) also demonstrated this association. Thus, differences in the association between HT and vitamin D 


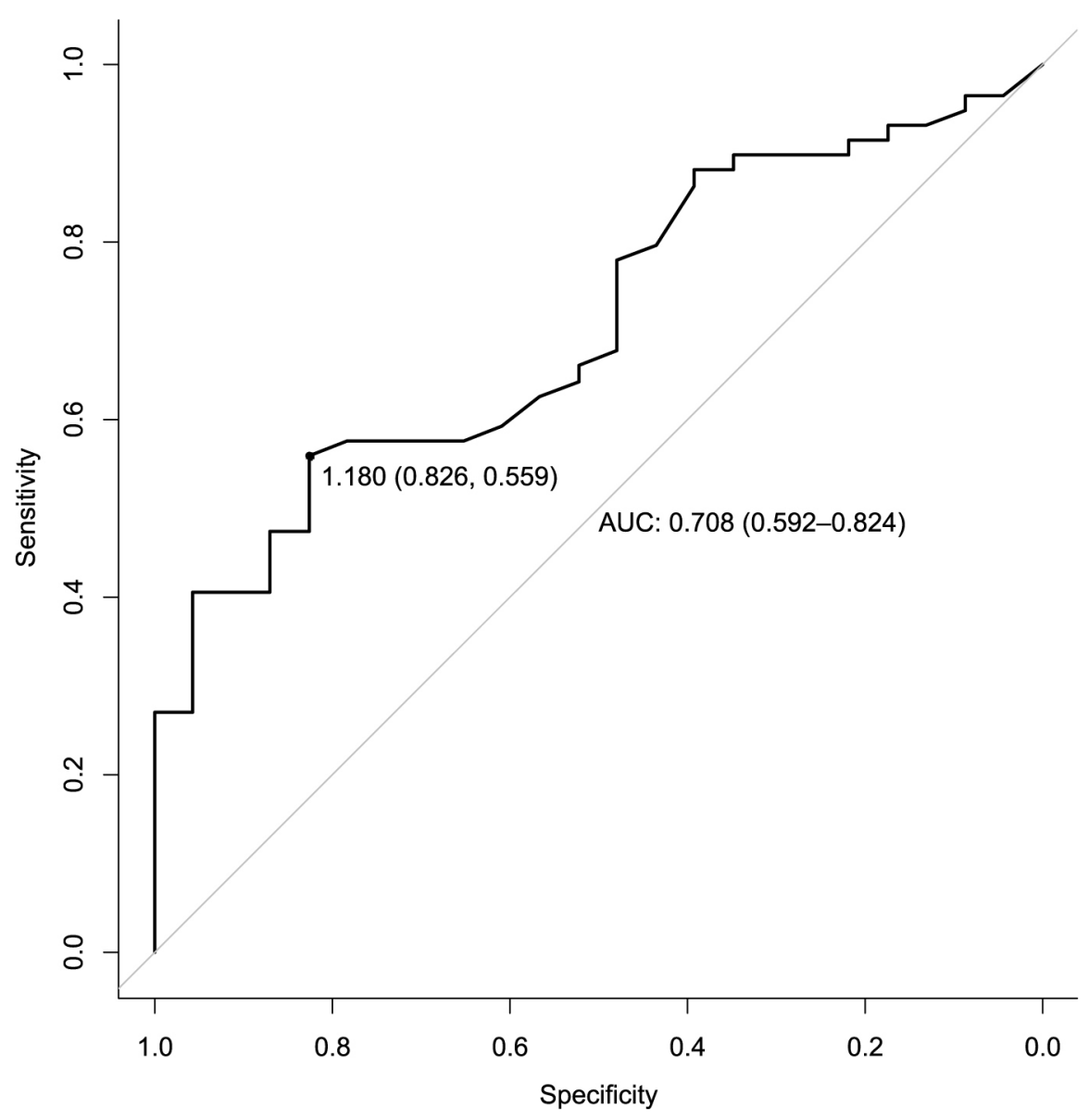

Fig. 1 ROC (receiver operator characteristic) curve used to identify threshold values related to insufficiency of $25 \mathrm{OHvitamin} \mathrm{D}(<30$ $\mathrm{ng} / \mathrm{mL}$ ) in patients with Hashimotos' thyroiditis. For a concentration of free thyroxine of $1.18 \mathrm{ng} / \mathrm{dL}$, sensitivity was $55.97 \%$, specificity was $82.6 \%$, and accuracy was $70.8 \%$.

insufficiency remain unresolved in the literature $[11,17$, 26-28, 34-36].

We emphasize that the reduction of free T4 levels was a predictor of vitamin D insufficiency for Hashimoto's thyroiditis, especially at concentrations below 1.18 $\mathrm{ng} / \mathrm{dL}$, but not for the euthyroid individuals of the control group, suggesting that the thyroid hormone status would play a role in the maintenance of vitamin D sufficiency, and its immunomodulatory role would influence the presence of autoimmune thyroid disease. Additionally, the positive correlation between free T4 and vitamin D concentrations suggests that adequate levothyroxine replacement in HT would be an essential factor in maintaining vitamin D at sufficient levels, similarly previous reports. Likewise, Bozkurt et al. (2013) demonstrated a direct relationship with vitamin $\mathrm{D}$ in patients with recent and long-standing HT and demonstrated that the severity of vitamin D deficiency correlated positively with dis- ease time and higher concentrations of anti-thyroid antibodies. Ma et al. (2015), D'Aurizio et al. (2015) and Ke et al. (2017) found no association between free T4 and TSH with vitamin D insufficiency in GD and HT. Zhang et al. (2014) observed in a cross-sectional study that higher concentrations of vitamin D were associated with low TSH, independent of free T4 values in euthyroid men from middle age to the elderly. Mansournia et al. and Tamer et al. found that vitamin D level presented decreasing trend in hypothyroidism patients who failed to administer medication. Krysiak et al. (2017) finding that vitamin $\mathrm{D}$ administration decreased thyroid antibody titers, especially TPOAb in HT women already receiving levothyroxine treatment suggesting that vitamin D may potentiate the effect of levothyroxine on autoimmune thyroid control [12, 17, 27, 36-40].

Additionally, lower concentrations of TNF- $\alpha$ was a predictor of lower levels of vitamin $\mathrm{D}$, pointing to the 
relationship between vitamin D and the immune system. This finding not corroborates data from the literature about the direct action of TNF- $\alpha /$ Th- 1 cytokines on the pathophysiology of HT and its presence in higher concentrations in vitamin D insufficiency. However, the patients in the present study had several years of established disease and were under treatment with levothyroxine, which could justify the low concentrations of TNF$\alpha$, a cytokine usually present in the disease development phase. Also, serum cytokine levels may be different from the levels within the thyroid cells $[7,10,12,26,39,41]$.

There was also a positive correlation between vitamin D and TNF- $\alpha$, IL-5, and IL-17. Low levels of TNF- $\alpha$ and IL-17 in detriment of low levels of vitamin $\mathrm{D}$, different from the literature description, could be justified by the control of cytotoxicity arising from the treatment of the disease since the patients of this study present in mean ten years of diagnosis and are on levothyroxine replacement therapy. Regarding IL-5, the literature has demonstrated, as in the present study, a positive association with vitamin D levels. According to Cantorna et al., vitamin D is associated with reduced production of cytokine group associated with cytotoxicity. Furthermore, a correlation was demonstrated between stimulation of autoantibodies, as well as higher concentrations of CD8 T lymphocytes and specific cytokines in the peripheral blood of patients with intense disease activity. Marchiori et al. observed reduction of pro-inflammatory cytokines in hypothyroid patients under treatment. On the other hand, Ke et al. (2017) not found an association with vitamin D levels and serum cytokines IL-4, IL-17 and TNF$\alpha$ in patients with HT and GD $[38,41,42]$.

In addition, we observed no association of vitamin D and thyroid volume, different from Bizzaro et al., 2015, who reported relation between low vitamin $\mathrm{D}$ and AITDs, anti-thyroid antibodies and higher thyroid volumes with higher levels of TSH, describing as a predisposing factor the VDR polymorphism present in cells of the immune system. Besides that, Pani et al. found polymorphisms in the vitamin D carrier protein (DBP) in GD but not in HT [43, 44].

Many researchers have been studied the single nucleotide polymorphisms (SNPs) in vitamin D receptor (VDR) to identify genes involved in the pathogenesis of autoimmune thyroid diseases (AITDs). Among the known polymorphisms related to the VDR locus are FokI, BsmI, ApaI, and TaqI. Ban et al. described the presence of VDR polymorphisms in both HT and GD besides the association between VDR-FokI polymorphism and risk of osteoporosis in GD. On the other hand, Giovinazzo et $a l$. found no relationship between VDR polymorphisms and the presence of HT unlike Lin W et al. who described a correlation between VDR-FokI polymorphism and the risk of developing TH [20, 45-48].

Interestingly, the correlation between vitamin $\mathrm{D}$ and PTH did not reach significance in both patients and controls. This finding may be justified due to the mean values of vitamin D in both groups were above $25 \mathrm{ng} / \mathrm{mL}$, not affecting calcium levels in general. Also, there was no correlation with vitamin D in both the patients' group and the control group. Although studies have shown that vitamin D levels below $30 \mathrm{ng} / \mathrm{mL}$ could lead to an increase in PTH, this did not happen in the present study $[19,49,50]$.

We considered as limitations of this study the small number of patients and individuals in the control group. However, it was possible to obtain significant results and we reached the number recommended by the sample calculation. Blood samples were collected in the months between spring and summer, however, in our region, the seasons do not show significant differences for sun offered during the months.

In conclusion, our study verified that lower levels of vitamin D have not been associated with HT, however thyroxine levels were determined as a risk factor for vitamin D insufficiency. We emphasize the importance of maintaining adequate concentrations of free $\mathrm{T} 4$ for the adequate vitamin D status in patients with HT, a fact not verified in euthyroid individuals. The association between vitamin D and TNF- $\alpha$, IL-5 and IL-17 in these patients pointed to the relevance to this relationship with autoimmunity in HT.

Additional studies are warranted to clarify the precise role of vitamin D in AITD.

\section{Acknowledgments}

The authors wish to thank FAPESP (Fundação de Amparo a Pesquisa do Estado de São Paulo), a public research support institution of the state of São Paulo, for full funding this study ( $\mathrm{n}^{\circ}$ 2012/20984-2).

\section{Disclosure}

None of the authors has any potential conflicts of interest associated with this research. 


\section{References}

1. Liontiris MI, Mazokopakis EE (2017) A concise review of Hashimoto thyroiditis (HT) and the importance of iodine, selenium, vitamin D and gluten on the autoimmunity and dietary management of HT patients. Points that need more investigation. Hell J Nucl Med 20: 51-56.

2. Orgiazzi J (2012) Thyroid autoimmunity. Presse Med 41: e611-e625.

3. Weetman A, DeGroot LJ (2016) Autoimmunity to the thyroid gland. www.thyroidmanager.org. Accessed jan $10^{\text {th }}$ 2018.

4. Bindra A, Braunstein G (2006) Thyroiditis. Am Fam Physician 73: 1769-1776.

5. So M, Macisaac RJ, Grossman M (2012) Hypothyroidism. Aust Fam Physician 41: 556-562.

6. Zantut-Wittmann DE, Persoli L, Tambascia MA, Fischer E, Franco Maldonado D, et al. (2004) HLA-DRB1*04 and HLA-DQB $1 * 03$ association with the atrophic but not with the goitrous form of chronic autoimmune thyroiditis in a Brazilian population. Horm Metab Res 36: 492-500.

7. Zha B, Huang X, Lin J, Liu J, Hou Y, et al. (2014) Distribution of lymphocyte subpopulations in thyroid glands of human autoimmune thyroid disease. J Clin Lab Anal 28: 249-254.

8. Li D, Cai W, Gu R, Zhang Y, Zhang H, et al. (2013) Th17 cell plays a role in the pathogenesis of Hashimoto's thyroiditis in patients. Clin Immunol 149: 411-420.

9. Colotta F, Jansson B, Bonelli F (2017) Modulation of inflammatory and immune responses by vitamin D. $J$ Autoimmun 85: 78-97.

10. Phenekos C, Vryonidou A, Gritzapis AD, Baxevanis CN, Goula M, et al. (2004) Th1 and Th2 serum cytokine profiles characterize patients with Hashimoto's thyroiditis (Th1) and Graves' disease (Th2). Neuroimmunomodulation 11: 209-213.

11. Mazokopakis E, Kotsiris D (2014) Hashimoto's autoimmune thyroiditis and vitamin D deficiency. Current aspects. Hell J Nucl Med 17: 37-40.

12. Tamer G, Arik S, Tamer I, Coksert D (2011) Relative vitamin D insufficiency in Hashimoto's thyroiditis. Thyroid 21: 891-896.

13. Effraimidis G, Wiersinga WM (2014) Autoimmune thyroid disease: old and new players. Eur J Endocrinol 170: R241-R252.

14. Proal AD, Albert PJ, Marshall TG (2009) Dysregulation of the vitamin D nuclear receptor may contribute to the higher prevalence of some autoimmune diseases in women. Ann N Y Acad Sci 1173: 252-259.

15. Perricone C, Agmon-Levin N, Shoenfeld Y (2013) Novel pebbles in the mosaic of autoimmunity. BMC Med 11: 101.

16. Choi YM, Kim WG, Kim TY, Bae SJ, Kim HK, et al.
(2014) Low levels of serum vitamin D3 are associated with autoimmune thyroid disease in pre-menopausal women. Thyroid 24: 655-661.

17. Ma J, Wu D, Li C, Fan C, Chao N, et al. (2015) Lower serum 25-hydroxyvitamin $\mathrm{D}$ level is associated with 3 types of autoimmune thyroid diseases. Medicine (Baltimore) 94: e1639.

18. Yang CY, Leung PS, Adamopoulos IE, Gershwin ME (2013) The implication of vitamin D and autoimmunity: a comprehensive review. Clin Rev Allergy Immunol 45: 217-226.

19. Holick MF, Binkley NC, Bischoff-Ferrari HA, Gordon CM, Hanley DA, et al. (2011) Evaluation, treatment, and prevention of vitamin D deficiency: an Endocrine Society clinical practice guideline. J Clin Endocrinol Metab 96: 1911-1930.

20. Lin WY, Wan L, Tsai CH, Chen RH, Lee CC, et al. (2006) Vitamin D receptor gene polymorphisms are associated with risk of Hashimoto's thyroiditis in Chinese pacients in Taiwan. J Clin Lab Anal 20: 109-112.

21. Unal AD, Tarcin O, Parildar H, Cigerli O, Eroglu H, et al. (2014) Vitamin D deficiency is related to thyroid antibodies in autoimmune thyroiditis. Cent Eur J Immunol 39: 493-497.

22. Ferreira CES, Maeda SS, Batista MC, Lazaretti-Castro M, Vasconcellos LS, et al. (2017) Official positioning of the Brazilian Society of Clinical Pathology/Laboratory Medicine (SBPC/ML) and the Brazilian Society of Endocrinology and Metabolism (SBEM)-Reference Intervals of Vitamin D-25(OH)D. J Bras Patol Med Lab 53: 377381 (In Portuguese).

23. Shoor N, Lips P (2017) Global overview of vitamin D status. Endocrinol Metab Clin N Am 46: 845-870.

24. Maeda SS, Kunii IS, Hayashi L, Lazaretti-Castro M (2007) The effect of sun exposure on 25-hydroxyvitamin D concentrations in young healthy subjects living in the city of São Paulo, Brazil. Braz J Med Biol Res 40: 16531659.

25. Martini LA, Verly E Jr, Marchioni DM, Fisberg RM (2013) Prevalence and correlates of calcium and vitamin D status adequacy in adolescents, adults, and elderly from the Health Survey-São Paulo. Nutrition Jun 29: 845-850.

26. Wang J, Lv S, Chen G, Gao C, He J, et al. (2015) Metaanalysis of the association between vitamin $\mathrm{D}$ and autoimmune thyroid disease. Nutrients 7: 2485-2498.

27. D'Aurizio F, Villalta D, Metus P, Doretto P, Tozzoli R, et al. (2015) Is vitamin D a player or not in the pathophysiology of autoimmune thyroid diseases? Autoimmun Rev 14: 363-369.

28. Effraimidis G, Badenhoop K, Tijssen JG, Wiersinga WM (2012) Vitamin D deficiency is not associated with early 
stages of thyroid autoimmunity. Eur $J$ Endocrinol 167: 43-48.

29. Brenta G, Vaisman M, Sgarbi JA, Bergoglio LM, Andrada $\mathrm{NC}$, et al. (2013) Clinical practice guidelines for the management of hypothyroidism. Arq Bras Endocrinol Metabol 57: 265-291.

30. Shabana W, Peeters E, De Maeseneer M (2006) Measuring thyroid gland volume: should we change the correction factor? AJR Am J Roentgenol 186: 234-246.

31. Agresti BF, Agresti A (1986) Statistical methods for the Social Sciences. Dellen Publishing Company.

32. Elliot AC, Hynan LS (2011) A SAS ${ }^{\circledR}$ macro implementation of a multiple comparision post hoc test for a KruskalWallis analysis. Comput Methods Programs Biomed 102: 75-80.

33. Conover WJ (1999) Practice Nonparametric Statistics. (3 $3^{\text {rd }}$ ed). John Wiley \& Sons Inc, Wiley.

34. Goswami R, Marwaha RK, Gupta N, Tandon N, Sreenivas $\mathrm{V}$, et al. (2009) Prevalence of vitamin D deficiency and its relationship with thyroid autoimmunity in Asian Indians: a community-based survey. Br J Nutr 102: 382-386.

35. Yasmeh J, Farpour F, Rizzo V, Kheradnam S, Sachmechi I (2016) Hashimoto's thyroiditis not associated with vitamin D deficiency. Endocr Pract 22: 809-813.

36. Zhang Q, Wang Z, Sun M, Cao M, Zhu Z, et al. (2014) Association of high vitamin D status with low circulating thyroid-stimulating hormone independent of thyroid hormone levels in middle-aged and elderly males. Int J Endocrinol 2014: 631819.

37. Bozkurt NC, Karbek B, Ucan B, Sahin M, Cakal E, et al. (2013) The association between severity of vitamin D deficiency and Hashimoto's thyroiditis. Endocr Pract 19: 479-484.

38. Ke W, Sun T, Zhang Y, He L, Wu Q, et al. (2017) 25Hydroxyvitamin D serum level in Hashimoto's thyroiditis but not Graves' disease is relatively deficient. Endocr $J$ 64: 581-587.

39. Mansournia N, Mansournia MA, Saeedi S, Dehghan J (2014) The association between serum 25OHD levels and hypothyroid Hashimoto's thyroiditis. J Endocrinol Invest 37: 473-476.
40. Krysiak R, Szkróbka W, Okopień B (2017) The effect of vitamin $\mathrm{D}$ on thyroid autoimmune in levothyroxine-treated women with Hashimoto's thyroiditis and normal vitamin D status. Exp Clin Endocrinol Diabetes 125: 229-233.

41. Cantorna MT (2010) Mechanisms underlying the effect of vitamin D on the immune system. Proc Nutr Soc 69: 286289.

42. Marchiori RC, Pereira LA, Naujorks AA, Rovaris DL, Meinerz DF, et al. (2015) Improvement of blood inflammatory marker levels in patients with hypothyroidism under levothyroxine treatment. BMC Endocr Disord 15: 32.

43. Bizzaro G, Shoenfeld Y (2015) Vitamin D and autoimmune thyroid diseases: facts and unresolved question. Immunol Res 61: 46-52.

44. Pani MA, Regulla K, Segni M, Hofmann S, Hüfner M, et al. (2002) A polymorphism within the vitamin D-binding protein gene is associated with Grave's disease but not with Hashimoto's thyroiditis. J Clin Endocrinol Metab 87: 2564-2567.

45. Ban Y, Ban Y, Taniyama M, Katagiri T (2000) Vitamin D receptor initiation codon polymorphism in Japanese patients with Graves' disease. Thyroid 10: 475-480.

46. Ban Y, Taniyama M, Ban Y (2001) Vitamin D receptor gene polymorphisms in Hashimoto's thyroiditis. Thyroid 11: 607-608.

47. Ban Y, Taniyama M, Ban Y (2000) Vitamin D receptor gene polymorphism is associated with Graves' disease in the Japanese population. J Clin Endocrinol Metab 85: 4639-4643.

48. Giovinazzo S, Vicchio TM, Certo R, Alibrandi A, Palmieri O, et al. (2017) Vitamin D receptor gene polymorphisms/haplotypes and serum 25(OH)D3 levels in Hashimoto's thyroiditis. Endocrine 55: 599-606.

49. Sadat-Ali M, Al-Omran AS, Al-Turki HA (2015) Parathyroid glands response to low vitamin D levels in healthy adults: a cross-sectional study. Ulster Med J 84: 26-29.

50. Díaz-Soto G, Julián MT, Puig-Domingo M (2012) Normocalcemic primary hyperparathyroidism: a newly emerging disease needing therapeutic intervention. Hormones (Athens) 11: 390-396. 